\title{
Anger and fear in decision-making: The case of film directors on set
}

\author{
Jean-Francois Coget , Christophe Haag , Donald E. Gibson
}

\begin{abstract}
Summary Anger and fear are frequently felt and impactful workplace emotions, especially in times of crisis when critical decisions need to be made. An important question is how these emotions might influence decision makers' depth of processing: whether when feeling angry or fearful decision-makers engage in more conscious and analytical rational decision making, or less-conscious and heuristic intuitive decision making. To date research on the effect of these strong emotions has been limited to laboratory studies where the complexity and pressures of real-world managerial decisions are absent, and focused on generalized mood rather than on direct emotional experience. This study asks two research questions: Do anger and fear facilitate the use of intuitive or rational decision-making? And what is the impact of these emotions on decision effectiveness? We examine these phenomena in the crisis-laden field setting of film directors actively engaged in directing motion pictures. Data were gathered by shadowing and interviewing seven film directors. A qualitative analysis of the video and audio transcripts revealed that film directors engage in two types of intuitive decision-making, based on whether the decision was driven by expertise or personal emotional experience. Rational decision-making occurred when directors, driven by feelings of moderate fear and little previous experience with a situation, relied on a more conscious, deliberative decision-making process. Four types of decision effectiveness are identified: task, personal, growth, and leadership. The implications of emotiondriven decision-making on each of these types of effectiveness are explored.

Published by Elsevier Ltd.
\end{abstract}

\section{Introduction}

Long gone is the time when researchers assumed that emotions played no role in decision-making (e.g., Von Neuman \&
Morgenstern, 1944). Since Simon $(1955,1968)$ first critiqued the rational decision-making paradigm, numerous studies have shown the importance of emotions in decision-making (for reviews, see Damasio, 1998; Forgas, 1995; Loewenstein \& Lerner, 2003). Neurobiological studies, for instance, have shown that it is impossible for people to make simple decisions when regions of the brain associated with emotion have been damaged (Damasio, 1998; Lieberman, 2000). 
One particular question that decision-making researchers have examined is how affect influences depth of processing; that is, whether people engage in systematic processing (rational decision-making) or heuristic processing (intuitive decision-making). By and large, studies on this topic have shown that when people are in a good mood they are more likely to engage in intuitive decision-making (Bolte, Goschke, \& Kuhl, 2003; Isen, 2000; Weiss \& Cropanzano, 1996), whereas when they are in a bad mood they are more likely to engage in rational decision-making (Elsbach \& Barr, 1999; Staw \& Barsade, 1993).

While these results are important, they do not specify how specific emotions influence the type of decision processing (rational or intuitive) in which an individual engages. This question is critical because other studies of emotion and decision-making have shown that emotions of the same valence (e.g., anger and sadness) can have quite different effects on decision-making (e.g., Keltner, Ellsworth, \& Edwards, 1993), calling for the need for studies that go beyond mere valence effects when studying how affect influences decision-making (Lerner \& Keltner, 2000).

To answer this call, this study explores the relationship between two discrete negative emotions, anger and fear, on decision-making. More specifically, we explore two questions. (1) Do the emotions of anger and fear facilitate the use of intuitive or rational decision-making? And, (2) What is the impact of anger and fear on decision-making effectiveness? We investigate these questions in the crisis-laden field setting of movie directors making decisions on set.

We focus on the emotions of anger and fear for several reasons. First, anger and fear are ubiquitous in both everyday life and work settings, and thought to affect decisionmaking (Averill, 1982; Kish-Gephart, Detert, Treviño, \& Edmondson, 2009; Lerner \& Keltner, 2001; Pekrun \& Friese, 1992). Second, studies of "basic" emotions have shown that they are among the most easily identifiable emotions in people's faces, gestures, and language (Ekman, 1994; Scherer, 1986). Finally, anger and fear naturally emerged as the most commonly occurring emotions in our setting. While we originally set out to study a variety of emotions in relation to decision-making, analysis of our data revealed that anger and fear occurred in $71 \%$ of all of our cases. We therefore decided to restrict our study to these two emotions.

We chose to investigate our question in a field setting first because the majority of studies on the role of affect in decision-making have been laboratory experiments, where time pressure and stakes are low, personal investment in decisions is imaginary, and the decision-making processes and outcomes studied are simple. This contrasts with the more complex real-world decision-making processes in which managers actually engage (Lipshitz, Klein, Orasanu, \& Salas, 2001), where affect may be found to have a different effect on decision-making than in the laboratory. For instance, the majority of laboratory experiments have found that when in a good mood subjects tend to perform better on creative tasks (Isen, Daubman, \& Nowicki, 1987; Isen, Johnson, Mertz, \& Robinson, 1985) associated with intuitive processing (Agor, 1991; Lubart \& Getz, 1997). However, in their field study of an organizational unit charged with developing creative designs, George and Zhou (2002) found that negative, rather than positive, mood facilitated on-the-job creativity in the unit they studied. In addition to these mixed results, researchers studying the decisionmaking of experts have expressed doubt that laboratory results can be generalized to contexts characterized by "ill-structured problems, uncertain, dynamic environments, shifting, ill-defined, or competing goals, multiple event-feedback loops, time constraints, [and] high stakes'” (Lipshitz et al., 2001: 334).

A second reason motivating us to investigate our questions in a field setting is that most existing studies on affect and decision-making have examined the influence of incidental rather than direct emotions on cognition. This research typically examines the effects of moods or emotions generated in one setting on cognitive processes in another setting. In intuition studies, for example, participants are induced to feel positive or negative affect and then given a task in which their depth of processing can be inferred (Tiedens \& Linton, 2001). However, measuring the influence of incidental emotion (emotion not related to the cognitive processing task that is presented) is not the same as measuring the effects of direct emotion (emotion that is relevant to participants, the situation they face, and the target of their expressed emotion). This is particularly important in situations likely to foster intuitive thinking, since theory suggests that intuitive processes involve affectively-charged situations and emotional neural pathways (Dane \& Pratt, 2007). We thus investigate our topic in a naturalistic rather than a laboratory setting. We examine the influence on decision making of emotions specifically generated by the situation of directing actors on a movie set. While the effects of anger and sadness on decision-making have been compared in laboratory studies, to our knowledge, no studies have compared and contrasted the effects of anger and fear on depth of processing, particularly in a field setting. We place our study within a growing tradition of qualitative studies of decision making in field settings, such as Hensman and Sadler-Smith (2011), Lipshitz and Shulimovitz (2007), Woiceshyn (2009), and Sadler-Smith and Shefy (2004).

\section{Theoretical background}

\section{Definitions}

Dual-processing theory: rational and intuitive decisionmaking

A number of psychologists have come to accept the notion of "dual-processing" in decision making (Adolphs, Tranel, \& Damasio, 2003; Bargh \& Chartrand, 1999; Damasio, 1998; Epstein, 1998; Kahneman, 2003; Kihlstrom, 1987; Loewenstein, 1996). Dual-processing is the idea that people process information with two distinct systems: a primary information processing system associated with intuition, and a secondary information processing system associated with reasoning (see summary in Salas, Rosen, \& DiazGranados, 2010).

The primary system has been characterized as fast, occurring outside of awareness, relying upon associations, holistic and synthetic, affect-laden, vivid, value-based, relying upon narratives, symbols, images and metaphors, based on experiential and tacit knowledge, relatively less intentional and effortful, and slow-learning (Agor, 1991; 
Burke \& Miller, 1999; Dane \& Pratt, 2007; Khatri \& Ng, 2000; Sadler-Smith \& Shefy, 2004; Sayegh, Anthony, \& Perrewé, 2004). Dane and Pratt (2007: 40), for example, define intuitions as "affectively charged judgments that arise through rapid, nonconscious, and holistic associations." In contrast, the secondary system is slow, conscious, relies on causal connections, is fragmented, affectively- and value -neutral, relies upon concepts and rules, is based on abstract and explicit knowledge, is relatively more intentional and effortful, and is fast-learning (Bargh \& Chartrand, 1999; Epstein, 1998; Kahneman, 2003). Table 1 summarizes the differences between intuitive and rational decision-making (or primary and secondary processing).

Research on the primary system has evidenced its connection with experience. As people repeatedly face the same stimuli or problems, they develop automatic ways of processing information about them and addressing them (Bargh \& Chartrand, 1999). This automation relieves the mind from having to process all information consciously, which would be prohibitively costly in cognitive terms (Kahneman, 2003). In certain cases, a single vivid exposure to a given stimuli might leave a strong imprint in memory, and constitute an experience that can influence intuitive processing (Brown \& Kulik, 1977).

While experience is typically unreflective or casual, expertise refers to a reflective and well-rehearsed type of experience developed by experts such as chess-masters, virtuoso musicians, athletes, or gifted mathematicians (Ericsson \& Charness, 1994). Research on experts has clearly established the link between repeated exposure to specific types of problem through practice and training (expertise) and the ability to excel in a domain of activity through effective intuitive decision-making (Dane \& Pratt, 2007; Ericsson \& Charness, 1994).

\section{Emotion}

Emotions are affective states that include physiological reactions and action sequences triggered by stimuli having meaning for individuals (Frijda, 1986; Lazarus \& Folkman, 1984). Emotions can be described in terms of their intensity-high or low-and their valence-pleasant or unpleasantand are generally of short duration (Feldman, 1995; Russell, 1999). While researchers initially studying decision-making assumed that cognitive processes always preceded emotional responses, it is now clear that emotions permeate individuals' perceptual processes and that affective judgments and reactions may precede cognition (LeDoux,
1996; Zajonc, 1980). Emotion as a construct is distinct from mood and affect. Moods are more diffuse, less intense, last longer than emotions, and have no clear cause (Ekman, 1994). In contrast to mood, emotions are sometimes labeled "discrete" 'because they are focused on a specific target or cause, such as the desire to approach objects in anger or to avoid them in fear (see Barsade \& Gibson, 2007; LeDoux, 1996). Affect is the generic term used to refer to both emotion and mood.

We distinguish intuitive decision-making from emotions by noting that the former is a non-conscious information processing system aimed at making judgments (Dane \& Pratt, 2007), while the latter are inputs to this process. Sadler-Smith further notes that "intuitions are feeling states that can be pinned down to a particular person, object, or situation, [but] the reason for the intuition [...] is less easily pinpointed"' (2010: 226), while emotions are more intense, of shorter duration, and the reason for the feeling is readily apparent.

\section{Do anger and fear facilitate the use of intuitive or rational decision-making?}

Our first research question has implications for studies that have found that positive mood facilitates the use of intuitive decision-making, while negative mood impedes its use in favor of rational decision-making (Forgas, 1998; Isen, 2000). For instance, individuals induced with a positive mood found more unusual associations between words (Isen et al., 1985), made better intuitive judgments about the coherence of word triads (Bolte et al., 2003), and performed better and faster when making complex decisions such as buying a car or making a medical decision than individuals induced with a negative mood (Estrada, Isen, \& Young, 1997; Isen \& Means, 1983). Other studies find that negative moods facilitate the use of rational over intuitive decision-making (Bolte et al., 2003; Keltner et al., 1993).

A number of recent studies on discrete emotions rather than moods, however, have shown that some negative emotions can facilitate the use of intuitive decision-making. For instance, several laboratory studies have compared and contrasted the role of anger and sadness on intuitive decision-making and have demonstrated that people induced to feel angry tend to engage in intuitive decision-making, whereas people induced to feel sad tend to engage in rational decision-making (Bodenhausen, Sheppard, \& Kramer, 1994; Lerner \& Tiedens, 2006). Tiedens and Linton (2001)

Table 1 Key differences between IDM and RDM.

\begin{tabular}{llll}
\hline & Intuitive decision-making & Rational decision-making & References \\
\hline $\begin{array}{l}\text { Type of cognitive } \\
\text { system involved }\end{array}$ & System 1: & System 2: & Dane and Pratt (2007), \\
& - Non-conscious & - Conscious & Epstein (1998), Kahneman \\
& - Fast & - Slow & (2003), Lieberman (2000) \\
& - Holistic & - Sequential & \\
$\begin{array}{l}\text { Type of knowledge } \\
\text { relied upon }\end{array}$ & - Associationistic & Abstract and explicit & Ericsson and Charness (1994) \\
$\begin{array}{l}\text { Involvement of affect } \\
\text { in the process }\end{array}$ & and expertise & knowledge & Dane and Pratt (2007), Janis \\
& Affect-laden and vivid & Affect-neutral & and Mann (1977), Sinclair and \\
& & & Ashkanasy (2005) \\
\hline
\end{tabular}


suggest that emotions associated with certainty appraisals (the belief that there are clear causes for life events and that coping with success and failure is possible), such as anger and happiness, are more likely to be associated with the use of intuitive decision-making, whereas emotions associated with uncertainty appraisals (the belief that life events are largely out of one's control and difficult to cope with), such as sadness or fear, are more likely to be associated with the use of rational decision-making.

One laboratory study (Katkin, Wiens, \& Ohman, 2001), however, finds evidence to the contrary, showing that visceral fear cues can help participants predict electric shocks. Fear can thus intuitively alert people to danger and provide them with a "gut feeling" on which to base a decision. Thus, extant laboratory studies have produced equivocal results: while positive mood has generally been shown to facilitate intuitive decision-making, and negative mood has generally been shown to facilitate rational decision-making, it is not clear that the same pattern holds true for discrete positive and negative emotions. In particular, no field study has examined whether anger and fear facilitate rational or intuitive decision-making. We therefore investigate this issue as our first research question.

\section{How do anger and fear influence decision effectiveness?}

Our second question regards the influence of anger and fear on decision effectiveness. To our knowledge, the literature is silent on this question. While Dane and Pratt (2007) filled an important gap in the literature by proposing factors that may influence the effectiveness of intuitive decision-making, discrete emotions were not among the factors they considered. Furthermore, to our knowledge, no empirical field study has investigated the influence of anger or fear on the effectiveness of decision-making. We thus address this question in our study.

The literature does provide tantalizing ideas about the relationship between discrete negative emotions and decision-making, but many questions remain. While laboratory studies have provided helpful insight into these dynamics, particularly in the context of rational decision making, they are less generalizable to settings where intuitive decisionmaking is most likely to be prevalent and critical: timepressured, complex actual organizational settings involving significant investment of personnel and resources. The "state of the art" in emotions and decision-making research is the suspicion that emotions are essential to the decision-making process in naturalistic settings, yet the specific ways specific emotions influence the process have not been examined. We suggest that the naturalistic setting of film direction provides an arena where the effects of felt anger and fear on decision-making can be examined in situ. Our methodology is described next.

\section{Method}

\section{Epistemological assumptions}

Our approach is that of "transcendental realists"; we believe that social and psychological phenomena exist in an objective plane, but that they are always filtered by the subjective experience that individuals, including researchers, have of them (Manicas \& Secord, 1983). More specifically, we categorize our epistemology as psychological phenomenology (Giorgi, 1994; Giorgi \& Giorgi, 2003). We are concerned with decision-makers' subjective experience of their own decision-making and emotions, and how the two relate. However, given our "transcendental realist" assumption, we recognize that people make decisions as the result of a confrontation with real (objective) events. For this reason, we adopt a qualitative method inspired from Coget (2009) dialogical inquiry paired with a grounded theory approach (Glaser \& Strauss, 1967). This method combines a dialogical methodology (Rowe et al., 1989) aimed at reconstructing the lived experience of participants making intuitive decisions in the field through an intersubjective empathetic dialogue, with a monological approach: the video analysis of decision-makers making intuitive decisions in the field (Jordan \& Henderson, 1995).

Our method was designed to triangulate (Jick, 1979) between (1) data from an initial interview, aimed at capturing key dimensions of a decision-maker's past experience; (2) video data of the decision-maker making decisions in the field, which constitute the most "objective" record of the situation; and (3) data from a second follow-up interview with the decision-maker, aimed at co-discovering, through a dialogical process, the subjective perception the decision-maker had of the situation. The investigators and the respondents co-constructed knowledge. This socially constructed knowledge, then, is more heavily biased towards the "native" point of view of decisionmakers (Geertz, 1975).

\section{Population and setting}

An important step for us was to identify a population and setting in which both rational and intuitive decision-making occur frequently and can be observed. Our review of the literature suggested that people are most likely to engage in intuitive decision-making when they have higher decisionmaking authority, when there is time pressure, and in crisis, complex, or uncertain situations (Dane \& Pratt, 2007; Sinclair \& Ashkanasy, 2005). Several populations and settings fit these requirements: firefighters confronting fires, soldiers in combat situation, police officers in the field, chefs in the kitchen, CEOs and high level officials in crisis situations, etc. Firefighters and soldiers have been the subject of several studies on intuitive decision-making (e.g., Kaempf, Klein, Thordsen, \& Wolf, 1996; Klein, 1998). Another population that would fit the boundary conditions likely to produce intuitive decision-making is film directors making decisions on set. To the authors' knowledge, intuition and depth of processing have not been studied with this population. A glossary of key terms commonly used in the film industry can be found in Appendix A.

First, when shooting a film, a director becomes the key decision-maker, having to make several crucial decisions per minute. By contrast, in pre- and post-production, other key players (e.g., the producer) become involved in decision-making. Second, in the production phase, the director's activity is crisis prone, complex, and subject to strong time 
pressures. Third, directing a film involves making many creative choices, which is associated with intuitive decisionmaking (Agor, 1991; Lubart \& Getz, 1997). Finally, emotions are often expressed more freely in the entertainment industry than in other settings (Bart \& Guber, 2002), which makes them more easily identifiable. Film directors in the production phase thus qualify as an adequate and interesting population and setting for this study. Following is a demographic summary of our sample.

Seven film directors were recruited for this study. The film school of a major West Coast University was a particularly rich source of contacts, yielding both direct participants (directing students) and access to professionals from the entertainment industry in Los Angeles. Although seven participants would be a small sample size for a quantitative hypothesis-testing study, it is appropriate for a qualitative study in psychological phenomenology, where the goal is to capture the rich subjective experience of the participants (Giorgi, 1994; Giorgi \& Giorgi, 2003).

Among the participants, three were professional film directors and four were film students at a major West Coast University shooting their Master of Fine Arts' thesis: a short film. Four were men and three were women. Their ethnic backgrounds were varied: one was African-American, one was Asian-American, one was Persian-American, and four were Caucasian Americans. Their ages ranged from 28 to 54 years, with an average of 39.6 years. They had directed from 2 to 7 films previously, with a median of 3 , and an average of 3.5. Although this number might seem low, it is actually typical of this industry where only the most prominent directors, among the lucky "100 in Hollywood," get to shoot films regularly (Smith, 1998). The study was reviewed and authorized by a university committee for the protection of human subjects. The crews working on the films ranged from 15 to 40 people, with an average crew size of 25 people, which is typical of independent film crews. Four of the films were short films, and three were feature-length films. Five of the films had very small budgets ranging from $\$ 20,000$ to $\$ 35,000$. The remaining two films had budgets of $\$ 300,000$ and $\$ 1000,000$, respectively.

\section{Data gathering protocol}

The first author gathered the data and he and the second author analyzed it. Prior to the shoot, the first author had an initial semi-structured interview with each director. The aim of the interview was to gain insight into the director's upbringing, previous directing and leadership experiences, management philosophy, and events that critically shaped his or her worldview. This interview allowed the first author to identify key experiences that might influence how the director intuitively made sense of events that naturally unfolded on set, and what types of situations might elicit strong emotions. On average, initial interviews lasted $1.5 \mathrm{~h}$.

During the shoot, the first author asked the participant directors to wear a wireless microphone and videotaped them while they were interacting with their crew and cast. Since film directors move constantly on set, it was impossible to film them from a fixed location and they had to be shadowed. Participants can become self-conscious when being filmed, which can distort their behavior. Four ele- ments limited this potential distortion. First, film sets are very public and crowded, which helped make the first author fade into the crowd. Second, crew members and directors are accustomed to cameras-a central tool of the trade-and to documentaries about the "making-of" the film being made. This made them less sensitive to the presence of the camera. Third, the action on film sets is so intense and the number of factors a director needs to attend is so high that the distraction of the camera appeared to recede quickly. Fourth, during intense situations in which the director might have become more self-conscious, the first author stepped away from the director while zooming from a distance to minimize interference. After the shoot, all of the participating directors indicated that they were only aware of the video camera in the first few minutes of the shoot and rapidly forgot about it.

The video record captured the whole situation the director perceived along with the director's reaction to the situation, which allowed for subsequent behavioral coding of emotions. Each director was shadowed for a full day of shooting, which yielded an average of nine hours of footage per director. Archival data was also gathered before and after the shoot: the call-sheet, the script, and the shot-list (see Appendix). These documents helped to identify the different crew and cast observed and their role, and to understand when the situation was deviating from the plan.

After the shoot, the first author analyzed the videotapes and selected critical incidents to be shown to the directors for commentary. Nine hours of footage per director can yield incidents in the hundreds. For practicality, an average of five to six critical incidents of one to five minutes per director were chosen, yielding a total of 41 critical episodes for the whole sample. The criterion to choose an incident was that it represented a crucial decision-making opportunity for the director. In order to recognize such instances, the first author acquired some knowledge about the craft of film directing before beginning the project. He attended a weeklong UCLA extension directing class taught by an experienced film director, and read various specialized books on film direction and production. He watched documentaries on film making, attended commented screenings, and socialized with various film industry specialists for over three years.

After all the data had been gathered, the second author watched the selected incidents on his own. In 7\% of the cases, he disagreed with the first author that the incidents were critical decision-making situations, which led to their exclusion from the sample, reducing the final useable sample to 38 critical incidents. The intercoder agreement for the degree of criticality of each decision-making incident is therefore $93 \%{ }^{1}$ (Miles \& Huberman, 1994).

\footnotetext{
${ }^{1}$ We report only inter-rater agreements for the coding of our data rather than the more conservative Cohen's kappa. We note that for the inter-rater agreement percentage we report in the Data Gathering protocol above, we did not code the whole $9 \mathrm{~h}$ of video per respondent in terms of incidents, and therefore do not have a total number of incidents, as required by Cohen's kappa. Furthermore, some researchers (e.g., Strijbos, Martens, Prins, \& Jochems, 2006) have expressed concern over the Cohen's kappa tendency to take the observed categories' frequencies as givens, which can have the effect of underestimating agreement for a category that is also commonly used. For this reason, Cohen's kappa can be considered an overly conservative measure of agreement.
} 
Approximately one month after selecting the critical incidents, the first author conducted a follow-up interview with the directors. This time delay allowed the directors to finish the film production phase, during which they were unable to focus on other activities such as this research study, and gave the first author time to select the critical events to be analyzed. This delay is consistent with other studies in phenomenological psychology (Harper, Lima, \& Craufurd, 2000; Smith \& Osborn, 2003).

The first author began each follow-up interview by asking the directors to recall the day they were videotaped and comment on significant incidents that stood out in their memory. The directors usually recalled one to three critical incidents, and in each case these incidents had already been included in the sample. The directors also confirmed that the additional incidents selected were indeed important decision-making instances. After this preliminary discussion, videotaped segments of the critical incidents and of events related to them were shown to the directors. The investigator let the directors describe the situation in their own words, taking care not to lead the conversation. Then, often paraphrasing the directors, or summarizing their statements, he further questioned them about what they were experiencing in the moment, trying to create a safe and empathic atmosphere conducive to the emergence of a perspective-expanding dialogue (Kohut, 1959). This empathetic dialogue allowed the directors to remember further details of their subjective experience and to resist artificially justifying their behavior after the fact (Weick, Sutcliffe, \& Obstfeld, 2005). On average, each follow-up interview lasted $2.5 \mathrm{~h}$ and was audio-taped. All the taped interviews and the videotaped episodes selected for discussion in the follow-up interviews were transcribed professionally and checked for content and accuracy by the investigators.

\section{Data analysis}

In a first round of data analysis, the first two authors watched all the video excerpts several times together in combination with the film directors' commentary to determine the coding scheme to be used to categorize the 38 critical incidents chosen. The authors chose to watch the videos together in order to further expand the perspective that was co-elaborated between the first author and the directors during the follow-up interview, in an effort to reach trustworthiness by "correcting" the limitations and misunderstandings of individual interpretations of reality (Habermas, 1990; Sandberg, 2005). As important categories emerged, the authors consulted the relevant literature on emotion to elaborate and standardize their coding scheme. Both the video excerpts and the transcripts of the initial and the follow-up interviews were coded and linked together.

For the transcripts, the unit of analysis chosen was a sentence or a multisentence unit. For the video excerpts, the unit of analysis was not specified quantitatively. Instead, video segments were coded with regards to the incident on tape and the commentary of the director (Jordan \& Henderson, 1995). Verbal exchanges were coded, but also significant changes in body position, gaze, gestures, etc. The authors particularly looked for behavioral clues that con- firmed or disconfirmed what the follow-up interview was revealing, in an attempt to achieve pragmatic and transgressive validity (for more information on these terms, see Sandberg, 2005).

In a second round, the first two authors independently watched each video excerpt and its associated commentary again, and systematically applied the coding scheme. The five following categories were retained: (1) discrete emotions felt by the film director; (2) the intensity of these discrete emotions for the director; (3) the type of experience or expertise, if any, mobilized by the director; (4) the type of decision-making (intuitive or rational decision-making) used; and (5) the effectiveness of the decision made. We now briefly expand on each of these categories.

The discrete emotions felt by the film director during each incident were coded in two ways: by direct observation of the video and by analyzing the subjective account captured in the follow-up interview. First, the film directors' facial expressions, gestures, vocal tone, and verbal cues were analyzed (Ekman, 1994; Scherer, 1986) to identify whether they expressed the emotions of anger or fear. Second, the directors' subjective accounts in the follow-up interview were analyzed to ascertain that they subjectively experienced these emotions during the incident. Each instance of anger or fear was coded for its intensity (moderate, or high). Incidents in which anger and/or fear were not experienced were rejected, which reduced the sample of critical incidents to 28.

The type of experience or expertise that the film directors mobilized, if at all, was determined in reference to the initial interview and the follow-up interview. When the respondent mentioned in the initial interview or in the follow up interview that they had expertise about the type of situation or issue faced, this instance of decision-making was coded as rooted in expertise. When they remembered an isolated non-task relevant experience that shaped their decision-making, this instance of decision-making was coded as rooted in personal experience.

For each critical incident, the decision-making process was coded as rational or intuitive decision-making. Based on the follow-up interview, the decision-making process was coded as rational decision-making when the film director remembered generating multiple possible courses of actions in the moment, evaluating them, and choosing one of them based on logical reasoning. The decision-making process was coded as intuitive decision-making when the director remembered reaching a decision fast, without analyzing the situation formally nor considering multiple alternatives.

The effectiveness of film-directors' decision-making is difficult to assess for at least two reasons. First, the work of film directors is artistic and therefore highly subjective. Second, it is difficult to evaluate how actions taken at the micro level of analysis chosen (one day of shoot) affected the whole film project at a macro level. Therefore, the directors' own after-the-fact subjective judgment was used as the criterion to assess the effectiveness of their decisionmaking.

The intercoder agreement reached on the application of the codes was of $89 \%$ (Miles \& Huberman, 1994). Both authors re-analyzed the cases in which they had disagreed and successfully resolved the disagreements. The authors then continued to analyze the incidents to form overarching 
codes, to subdivide codes, and to discover relationships among codes. As they did so, they started to elaborate the model of anger, fear and decision-making that will be presented in the findings section. The authors expanded and refined the model by comparing and contrasting the different incidents until the model stopped evolving and theoretical saturation was reached (Miles \& Huberman, 1994).

\section{Findings}

This study aimed to answer two questions: Do anger and fear respectively facilitate the use of rational or intuitive decision-making? And how do they influence decision-making effectiveness? First, we provide a preview of our findings, which we illustrate in Table 2. Second, we elaborate our findings in depth and illustrate them with multiple quotes.

In attempting to answer our first question, we inductively developed a new typology of decision-making. More specifically, we found that film directors engage in two types of intuitive decision-making: expert-intuitive decision-making and emotional-intuitive decision-making. Expert-intuitive decision-making occurs when directors, driven by feelings of moderate anger, draw upon their professional expertise about a given situation. Emotional-intuitive decision-making occurs when directors, driven by feelings of high intensity fear or anger and no previous expertise with a situation, conjure up personal emotional experiences. A third type of decision-making, rational decision-making, occurs when directors, driven by feelings of moderate fear and little previous experience with a situation, rely on a more conscious, deliberative decision-making process.

In attempting to answer our second question, we inductively developed a typology of decision-making effectiveness. Directors do not judge their decision-making as simply effective or ineffective. Rather, they emphasize four types of effectiveness based on the decision-making they are engaged in: (1) task effectiveness, (2) personal effectiveness, (3) personal growth, and (4) leadership effectiveness. Task effectiveness indicates a focus on the resolution of external problems and the achievement of professional goals. Personal effectiveness refers to directors' internal functioning: the extent to which they remain calm, balanced, and motivated so that they can keep functioning at their highest ability throughout the busy day of a shoot.

Table 2 Anger and fear in IDM and RDM.

\begin{tabular}{|c|c|c|c|c|}
\hline Type of decision making & Expert IDM & \multicolumn{2}{|l|}{ Emotional IDM } & RDM \\
\hline Definition & $\begin{array}{l}\text { Directors, driven by } \\
\text { feelings of moderate } \\
\text { anger, draw upon } \\
\text { their professional } \\
\text { expertise about a } \\
\text { given situation to } \\
\text { make an intuitive } \\
\text { decision }\end{array}$ & \multicolumn{2}{|c|}{$\begin{array}{l}\text { Directors, driven by feelings } \\
\text { of high intensity fear or } \\
\text { anger and no previous } \\
\text { expertise with a situation, } \\
\text { conjure up personal emotional } \\
\text { experiences to make an intuitive } \\
\text { decision }\end{array}$} & $\begin{array}{l}\text { Directors, driven by } \\
\text { feelings of moderate fear } \\
\text { and little previous } \\
\text { experience with a } \\
\text { situation, rely on a } \\
\text { conscious, deliberative } \\
\text { decision-making process }\end{array}$ \\
\hline $\mathrm{Nb}$ of cases & 5 & 14 & & 9 \\
\hline \multicolumn{5}{|l|}{ Antecedents } \\
\hline Previous experience & Expertise & $\begin{array}{l}\text { Personal } \\
\text { emotional } \\
\text { experience or Lack } \\
\text { of previous } \\
\text { experience }\end{array}$ & & $\begin{array}{l}\text { Lack of previous } \\
\text { experience with the } \\
\text { situation }\end{array}$ \\
\hline Emotion & Moderate anger & High anger or & High fear & Moderate fear \\
\hline \multicolumn{5}{|l|}{ Decision making effectiveness } \\
\hline $\begin{array}{l}\text { Task effectiveness } \\
\text { The resolution of external } \\
\text { problems and the achievement of } \\
\text { professional goals }\end{array}$ & Main focus & $\begin{array}{l}\text { Pursued } \\
\text { aggressively }\end{array}$ & Decreased & Achieved \\
\hline $\begin{array}{l}\text { Personal effectiveness } \\
\text { Extent to which directors remain } \\
\text { calm, balanced, and motivated so } \\
\text { that they can keep functioning at } \\
\text { their highest ability }\end{array}$ & $\begin{array}{l}\text { Achieved } \\
\text { automatically through } \\
\text { feelings of mastery }\end{array}$ & $\begin{array}{l}\text { Achieved } \\
\text { automatically } \\
\text { through feelings of } \\
\text { mastery }\end{array}$ & $\begin{array}{l}\text { Achieved by } \\
\text { avoiding threats }\end{array}$ & $\begin{array}{l}\text { Slightly diminished } \\
\text { because it demands more } \\
\text { cognitive resources }\end{array}$ \\
\hline $\begin{array}{l}\text { Leadership effectiveness } \\
\text { Directors' ability to build or } \\
\text { strengthen their relationships } \\
\text { with their crew and cast }\end{array}$ & & Decreased & & \\
\hline $\begin{array}{l}\text { Personal growth } \\
\text { Directors learn something new or } \\
\text { build their expertise }\end{array}$ & & & & Occasionally achieved \\
\hline
\end{tabular}


Personal growth occurs when directors learn something new or build their expertise. Finally, leadership effectiveness refers to directors' ability to build or strengthen their relationships with their crew and cast.

When engaged in expert-intuitive decision-making, movie directors emphasize task effectiveness. However, they also achieve personal effectiveness automatically as their expertise provides them with a sense of confidence. The effectiveness of emotional-intuitive decision-making depends on whether it is triggered by high fear or high anger. In the case of high fear, directors emphasize personal effectiveness at the expense of task effectiveness: they abandon their professional goals and their focus on external problems to focus on resolving their inner distress. In the case of high anger, directors emphasize task effectiveness, aggressively pursuing their professional goals and automatically achieving personal effectiveness by doing so. However, this type of effectiveness is achieved at the expense of leadership effectiveness: relationships are often weakened or damaged in the process. Finally, when engaged in rational decision-making, movie directors emphasize task effectiveness at the expense of personal effectiveness: they brave their fear in order to tackle external problems. In doing so, they achieve personal growth as they discover solutions to new problems and build their expertise. Table 2 summarizes these findings.

In summary, the type of decision-making that directors engage in and their effectiveness depend on the type of emotion they feel (anger or fear); their intensity (moderate or high); and the type of previous experience they have with the situation they face (expertise, personal experience, or lack of previous experience). Next, we elaborate the evidence supporting these findings by analyzing in depth the three types of decision-making we found directors using on set: expert-intuitive decision-making, emotional-intuitive decision-making, and rational decision-making. In each case, we discuss their antecedents and their effectiveness.

\section{Expert-intuitive decision-making}

Respondents describe both expert and emotional intuitive decision-making as a non-rational, instinctive process that is difficult to explain. One director captured this typical response as,

How do I do it? Man, you know, it's like intellectualizing to verbalize something that's so instinctive.

However, one of the key features that differentiates expert-intuitive decision-making from emotional-intuitive decision-making is the presence of expertise (see Kahneman \& Klein, 2009; Salas et al., 2010). Elaborating on how he was able to make an intuitive decision, the same director noted:

It's about experience and repetition and wisdom, you know... many, many classes, many, many years, many plays, many experiences, many studies, watching a thousand movies, travelling all over.

Indeed, research on experts has clearly established the link between repeated exposure to specific types of problems through practice and training and the ability to make decisions accurately and fast (Ericsson \& Charness, 1994;
Simon, 1987). Through expertise, movie directors are able to recognize and match patterns in a present situation with similar patterns in previous situations. This allows them to make an intuitive decision that resolves an external problem and achieves task effectiveness. One director, for instance, decided to switch from "flame-bars" to "orange lights" to simulate the visual effect of an explosion on his actors' faces based on his expert understanding of safety:

When a special effects guy tells you that he has a safety concern and you ignore that, as a director, you're responsible. It all goes back to the 'Twilight Zone' disaster where the actor... and the two kids were killed... Helicopters were supposed to come down toward [the actors] and they were supposed to run away.... and these explosions were supposed to go off. And every take, the director told the helicopter guy to come in lower and. . . telling the pyro guys to make the explosions bigger. And so at one point, the helicopter came in directly over a big pyro charge... and it crashed into the water and it cut off the head of the lead actor... and killed both of the Vietnamese children... and it was the fault of the director.

In all of our cases of expert-intuitive decision-making directors gave indication that they had expertise, either in the follow-up interview or in the initial interview. They indicated that they experienced a moderate form of anger. In the example described above, for instance, the director commented:

I was annoyed the first time it happened days before this [referring to safety concerns that led to diminished special effects]... I think if I had been really expecting it and depending on it, I would have freaked out. But I just knew these guys' [referring to the special effects crew] modus operandi: they're about the most minimal, safest way to do anything.

As evidenced in the quote, expertise helps directors regulate their anger by providing them with a sense of control over the situation. Conversely, anger mobilizes memories that elicit expertise. For instance, one director commented on her intuitive decision to ask her set designer to store crucial props in a safe place:

As much as I was in love with the actors and the characters... I was in love with the ideas of these props... I just- yeah, I just want to protect them and make sure that... no Joe-Schmo comes along and just like drops a fu*king light on it and that's it, you know?

The moderate anger that she felt motivated her to protect the props based on memories she had of a previous shoot during which a crucial prop was dropped and broken:

I think if something flashed into my brain it might've been the Death Valley shoot where... one of my crew dropped something on the space helmet and it broke. We had to go home... and wrap. I just remember like, getting to the motel and crying... And it was the first time l've ever cried on a set.

Anger and expertise thus recursively influence each other. When engaging in expert-intuitive decision-making, movie directors focus on task effectiveness and goal achievement. For instance, one of the directors commented 
the following about her decision to keep a child actor working beyond prescribed hours in order to get the scenes she needed:

I didn't want to have this conversation with the Mom but I had to... We were under the bullet and the kid was tired, and I knew he was tired, but I needed a few more things with him before we stopped. . So, I looked at the teacher for like some kind of approval but the teacher just rolled her head and was like boring her eyes into the head of the Mom, you know, hoping that she would turn around, but the Mom didn't turn around... And I looked at the teacher and I realized that she wasn't going to do anything, so I turned around and I was like "I won," [laughs] and I was like "What a b*tch!" And then I started laughing 'cause I thought about her face and like how intense and funny it was.

When achieving their goals, directors automatically achieve personal effectiveness because they feel confident. Next, we elaborate on emotional-intuitive decision-making.

\section{Emotional-intuitive decision-making}

Emotional-intuitive decision-making is similar to expertintuitive decision-making in that they both are non-rational, instinctive processes that do not involve the generation of multiple alternatives and their analysis. However, in emotional-intuitive decision-making, the decision-making process is driven by strong emotions rather than by expertise. One director commented on the way high anger drives her decision-making:

I use [anger] as an excuse to say what l've been wanting to say and it comes out in such a volcanic way that no one can argue with that. Just, boom, I'm over the edge and everything comes out.

In emotional-intuitive decision-making the strong emotions directors feel are often related to vivid personal experiences they had that inform their understanding of the situation. One director, for instance, decided to fight rather than accommodate the way her elderly Chinese actress acted her part based on feelings of anger she had for her own Vietnamese, ethnic Chinese grandmother, who her actress reminded her of:

She [the actress] was like my maternal grandmother, who moved to the United States from Vietnam. . . I didn't speak her language. She didn't speak mine, and so we were never really able to communicate... She'd see me and she'd just say "You wear too much black!", you know, "Why don't you know how to speak Chinese?" and she was very critical.

In another example, the director decided to adopt a "strong-armed" strategy to retain an actress who had threatened to quit:

I wanted to get her alone to make it absolutely clear... that I have absolutely no fear or need of her threat so she knows that she can do that all night and it's going to be completely ineffective, okay? We learn that in the streets: when a guy points a gun at you, nine out of ten times, he's not going to pull the trigger. He's going to scare you. So. . . the first thing you say to him is 'you'd better shoot me because l'll kill you when you take it off. Now that you've pulled it, you'd better kill me because you're dead. You threatened my life.' At that point, you're gonna know his commitment, because if he's going to kill you, you're dead anyway.

This director's strategy was rooted in his personal experienced during his adolescence as a gang member in Los Angeles, which he recounted in the initial interview.

In a second set of cases the directors lacked any form of experience with a situation, whether personal or rooted in expertise. In these cases, their decisions were driven by the emotion itself. In one such example, the shoot was interrupted when a train stopped next to the set, which was located by railroad tracks. The sound of the train's engine ruined the shot. The train conductors were looking with apparent curiosity at the set. Although the director had never faced such a situation before, she reacted quickly by giving in to her strong anger:

I felt frustrated. It's like "Oh, God! Enough!' [a helicopter had caused a similar sound issue earlier in the day] I was standing there going like this [gesturing wildly] "Go!" I'll tell you, it's exhausting. I must have been exhausted then, man. I'm exhausted just looking at it, you know?

The focus of the decision-making effectiveness differed in the cases of emotional-intuitive decision-making associated with high anger versus high fear. In the case of high anger, directors give priority to task effectiveness, also automatically achieving personal effectiveness because they achieved their goals, but possibly damaging their leadership effectiveness. In one case, for instance, the director decided to fire her main actress before she had shot any scene because she proved to be too difficult to direct:

I can feel myself getting angry just hearing that and that... She really got me angry... I'm really $p *$ ssed... I thought, 'She's just gonna keep doing this!' And I was getting more and more solidified: this ain't gonna $f * c k i n g$ continue. . . I didn't say, 'You're fired', I said, 'It's over. That's it.' I'm easygoing but when I feel control is being taken, then I don't like it, you know? And I fight against it.

While the director felt effective addressing the immediate problem by replacing the difficult actress with an easier one that was standing by for the role, she expressed ambivalence at the potentially negative leadership effect of her outburst on her crew and cast:

What was I doing, marching out of there [the make-up trailer] saying "it's over'? They [the crew and cast] didn't need to know it in that way. . I think I should have probably just kept my mouth shut and just go on- but that was sort of letting out my emotion, I think. I was so angry with - I was just really p*ssed. Yeah, I was getting it out. I wish l'd contained it. . I think it would have been a little more dignified, you know? I shouldn't have done that in front of my crew. I mean, they all knew or they would have found out.

In the case of emotional-intuitive decision-making associated with high fear, directors give priority to their 
personal effectiveness at the expense of their task effectiveness. In one case an actress was to display intense emotions as her husband, whom she had believed to have been hurt in a car accident, showed up at home, unharmed. The actress looked very tense as she was preparing for the scene. The director decided to let her play as she had intended, despite the fact that he did not like her performance because he experienced intense fear:

It's an emotional scene. This is her close up and she is wound so tight and I'm starting to recognize this right now... She wanted her space, she was very concentrated, very focused, [which is] a bad thing. . . because actors can't act when they're wound tight.... [It felt] like hearing a rattlesnake's rattle... She's locked and loaded, whatever she is going to do, she is going to do... Once I saw that tension, I adjusted to it.

The director commented that his reaction resulted in a less-than-optimal outcome; he had responded to his own fear and need to personally cope with the fear, rather than focusing on task effectiveness: shooting the scene in a way to provide further options:

I knew that I was shooting stuff that I probably wouldn't be able to use, that it was a little too peaked thematically for what was going on in my scene... I think if I'd had more experience I would've pulled it back... In my mind, I saw my cut as being... the daughter's scene... By shooting it with different angles, at that moment I would probably be watching the daughter in terms of the audience. So that's what was primarily going through my head... At the same time it scares me because... I try to shoot it so all the content is good to give extra solutions, more options in editing because you never know what it's gonna look like, until after the editing process. I could have stepped in and pulled it back... and I probably should have... I was thinking about my solution as opposed to going and getting all the scenes the way I visualized them.

Next, we elaborate on rational decision-making motivated by moderate fear.

\section{Rational decision-making}

Besides expert-intuitive decision-making and emotionalintuitive decision-making, we also observed directors engaging in rational decision-making. When engaging in rational decision-making, directors considered, analyzed, and evaluated multiple alternatives. In all of the cases in which they used rational decision-making, directors had neither expertise nor personal experiences that allowed them to easily make sense of the situation, which explains why they had to take the time to analyze it rationally. They also experienced a moderate level of fear, which motivated them to address an external problem through rational decision-making. For instance, in one case, the director had to figure out the exact choreography of a group of motorcycles driven by stunt artists throughout multiple shots. The scene represented a motorcycle gang encircling the two protagonists and performing jumps and various imposing stunts. The director commented on the episode:
I remember now being a bit scared. It's like, "Jesus Christ. I thought we had this done. I mean, this is so huge." It seemed like such a huge task. It was really choreography of where those bikes were going. And I was like, "Oh, my God. How are we gonna do this?" I thought I had done that with [my director of photography] already, that we had gone through this. But it's like, okay, now we've got to do it again... So, I called [my script supervisor] in to... write this down... I was taking steps. . . and I needed that written down because I wasn't gonna remember it all.

When engaging in rational decision-making, directors focus on task effectiveness at the expense of their personal effectiveness or comfort. The previous director commented the following on the effectiveness of her rational decisionmaking:

[The script supervisor] was really organized and really good... She was extremely helpful. It worked.

Also, when engaging in rational decision-making, some directors achieved personal growth because they learned something new, thus building expertise. One director made the following comment on his decision to abandon elaborate shooting plans and move faster because of difficult weather conditions:

It was $f{ }^{*}$ cking cold. And at one point, the wind was so intense that the Musco light operator was starting to bring his light down... because he was scared to have his light up in the air. And so I had to start moving faster and faster and faster... And you have a pressure in the afternoon to get it finished before it gets dark... So the pressures of having cold actors, cold crew members, me being cold, a light operator who was pulling my light down and making all the lighting look weird added up... Everybody wanted to get the $f * c k$ done with it. . . So, people eventually started moving faster and with urgency... So, I had a discussion with my line-producer about abandoning my plan of coverage and doing something simplistic that just got this in the can. So we accomplished it. I mean we- it's kind of like, we didn't know what we were doing. . . but it's nice, clean coverage, and each angle is there that I needed, and it's a fine scene. It's pedestrian. And in its coverage that's very uninventive, but I was uninventive for practicality' sake... It was a good problem-solving approach... Well I'm proud. No one will ever know this, but considering the circumstances this is really good.

\section{Discussion}

\section{Theoretical contributions}

This study's goal was to examine the effect of two specific emotions, anger and fear, on decision-making. While previous research has proposed that emotions influence depth of processing (e.g. Isen et al., 1985), the dynamics of this relationship have not been fully examined, particularly in the context of direct emotional experiences in real-as opposed to laboratory-decision environments. Moreover, the focus of previous studies has been on relatively simple dichotomies: 
between negative/positive valences and depth of processing. These studies primarily find that negative emotional states tend to lead to more systematic cognitive processing characteristic of rational decision-making, while positive emotional states lead to intuitive decision-making (e.g., Bolte et al., 2003; Isen, 2000). Later studies using discrete emotions reveal that certainty emotions (such as anger) are more likely to lead to intuitive processing than uncertainty emotions (such as fear; Tiedens \& Linton, 2001).

Our findings add nuance, complexity, and specificity to these relationships. The typology we inductively developed suggests that not only should specific emotions, such as anger and fear, be delineated, but their intensity (moderate versus high) must also be considered. These emotional states recursively influence and are influenced by the decision maker's level of expertise and personal experience-or their perceived lack of experience-when confronting a particular situation. This combination of felt emotion and perceived experience affects the type of decision-making used, and the degree to which a decision outcome is regarded as effective, based on task, personal, or leadership effectiveness.

Do anger and fear facilitate the use of intuitive decisionmaking or rational decision-making?

This question helped us to address and elaborate on previous understandings of the process of emotion and decision-making. First, this study contributes to the literature on emotion and intuition by investigating a rarely-studied emotion, fear, in relation to intuitive decision-making. Previous studies have found that specific emotions associated with an appraisal of uncertainty, such as sadness, are associated with a tendency toward greater use of rational decision-making (e.g. Tiedens \& Linton, 2001). While we expected that fear would fit this previously identified pattern, our findings revealed a more specific relationship: the model proposes that moderate intensity fear facilitates rational decision-making, while high intensity fear facilitates a form of intuitive decision-making that leads the decision maker to abandon important professional goals.

Second, our findings suggest that the research question above, focusing as it does only on the presence of a particular emotion and a dichotomy between intuitive decisionmaking and rational decision-making, is too simple. Rather, a key determinant of the type of decision-making used in this study was the intensity of the anger and fear felt (see Frijda, 1986; Hodgkinson, Langan-Fox, \& Sadler-Smith, 2008). All of the decisions we examined were by definition emotional; what varied was their intensity, and this intensity, coupled with respondents' perception of whether they had the expertise or experience to cope with their emotion, determined the type of decision-making they used.

Third, we find an important distinction between expert and emotional intuitive decision-making. Expert-intuitive decision-making has been the primary focus of previous studies: intuitive decision-making has primarily been characterized as driven by experience made up of explicit and tacit knowledge and emotions are a contributor-sometimes for the better, sometimes for the worse-to this process (see Kahneman \& Klein, 2009; Khatri \& Ng, 2000; Klein, 1998; Salas et al., 2010; Sayegh et al., 2004). In our study, situations evoking moderate anger were most likely to lead to ex- pert-intuitive decision-making, a relationship unexamined in previous research. We then develop a new concept, emotional-intuitive decision-making, suggesting that, in addition to past experience, intuitive decision-making may also be driven by emotions. In these situations, high anger or high fear appears to make salient emotional memories consistent with personal experience (see Sayegh et al., 2004), or a perception that an adequate experience base does not exist for making a rational decision. It is interesting to note that when high anger or high fear drives intuitive decision-making, the benefits of intuition (rapid decisionmaking under stressful conditions) are accompanied by a cost: in the case of high anger, task effectiveness comes at the expense of leadership effectiveness, and the group or organization may suffer; in the case of high fear, personal effectiveness is accomplished at the expense of task effectiveness. In this case, the effort to cope with high fear and attend to one's individual needs may distract decision-makers from their task goals.

Our newly proposed concept of emotional-intuitive decision-making furthers the debate about the distinction between emotion and intuitive decision-making. Sadler-Smith (2008), Sadler-Smith (2010) proposes that intuitions are less intense, longer in duration, and have a less clear cause than emotions. While his conceptualization is useful in distinguishing expert-intuitive decision-making from emotion, it is less useful to distinguish emotional-intuitive decision-making from emotion itself. Following Damasio (1998) conceptualization of emotion and feeling, we suggest that intuitions are a particular type of feeling, which are cognitive elaborations of emotion - a somatic process. Emotions therefore serve as inputs to the process of intuitive decision-making; they are not the same as intuitions.

\section{What is the impact of anger and fear on decision effectiveness?}

Our model indicates that, in determining the impact of emotions on decision-making effectiveness, we must add more specificity to the antecedent emotions, in the sense of considering intensity. Our findings also suggest that we must add more specificity to our outcome variable, by delineating what kind of effectiveness. It is not enough to determine whether a decision was dichotomously effective or not, but rather, effective in terms of what aspects of the decision and situation. For example, we find that both high anger and high fear led to intuitive decision-making in our respondents. The difference was in the outcome-how these emotions influenced task, personal, and leadership effectiveness. In this sense, high levels of anger felt by directors have the potential to lead to more effective task outcomes than high levels of fear, a relationship that should be examined in further field research.

Our model contributes to further understanding of intuitive decision-making effectiveness. In the case of anger, our model provides empirical support for Dane and Pratt (2007) theoretical prediction that intuitive decision-making is more effective when it relies on domain relevant expertise than on personal experiences: we found that when anger was associated with past professional situations, intuitive decision-making was more effective than when anger was associated with personal situations. However, in the case of fear, our findings provide a new picture: moderate fear 
leads to moderately effective rational decision-making, whereas high intensity fear leads to ineffective intuitive decision-making. These predictions cast a new light on our understanding of decision-making effectiveness.

\section{Further research}

We have emphasized that the decision-making of movie directors on set is characteristic of a range of settings where decision-making takes place under time-pressured, actionoriented, highly fluid situations. While we believe this type of decision-making is generalizable, it is important to note that while the directors studied did confront "crisis" decisions, especially in terms of actors to use and artistic choices, these crises may not be comparable with the crisis situations of firefighters or military commanders that have been the focus of past intuitive decision-making research (e.g., Klein, 1998). Further studies could therefore examine other settings to extend the generalizeability of our findings. On a related note, the nature and culture of the entertainment industry may make expression of emotions more acceptable than other organizational settings. Thus, our findings pertaining to high anger and fear may reflect this higher acceptance-and lower regulation-of emotional response (see Geddes \& Callister, 2007). This factor makes this an appropriate initial setting to explore more extreme examples of emotional feeling and expression; further study should examine settings where norms for appropriateness dictate more subdued expression.

An area of this study that could be re-visited in future research is the way decision-making effectiveness was measured. We used the participants' after-the-fact selfassessment of their decision-making as a measure of their effectiveness. The point of view of the participant could be biased. For instance, in the example in which a director decided to keep her child actor working beyond prescribed hours, it could be argued that the decision was operationally effective, but unethical. The findings may therefore reflect whether participants regretted their intuitive decision-making rather than whether their intuitive decision-making was effective. Further studies should therefore seek to measure intuitive decision-making effectiveness in multiple ways, triangulating among them.

It would also be interesting to explore in further studies the mechanisms through which different discrete emotions influence the process of intuitive decision-making. While this study provides us with a better understanding of how anger and fear influence depth of processing, we did not investigate how they may influence the process of intuitive decision-making itself. Lerner and Tiedens (2006) suggest a range of mechanisms for the effects of anger on decision processes and outcomes. It would be interesting to expand these suggestions in conjunction with our findings, and test them in further studies.

\section{Practical implications}

While this study's findings must be considered exploratory, there are several practical implications. This study suggests that decision makers should monitor their emotions as important signals of their response to the situations con- fronting them and the likelihood that they will engage in effective decision-making. Feelings of moderate (and thus controllable) anger may alert decision makers that drawing on past expertise may be possible and that their intuitive "gut feelings" may be helpful. Feelings of high anger should indicate that decisions directly resolving the task may occur, but leadership effectiveness could be compromised. Indeed, stories abound in the entertainment industry of leaders who allow their anger "tantrums" to hinder personal relationships and their ability to effectively lead their organizations. Directors such as Oliver Stone and Alfred Hitchcock are notorious cases in point. Feelings of moderate fear or anxiety should signal to decision makers that time should be taken to consider choices carefully and perhaps seek outside advice. Feelings of high fear should provide cautions to decision makers that likely they are focusing on the personal history and implications of a particular situation rather than on aspects of the task itself. While we are aware that monitoring emotions while they are being felt is difficult, understanding these relationships ahead of time could help a decision maker to better understand his or her emotional tendencies and their potential outcomes in the heat of crisis decision-making.

\section{Conclusion}

There has been great progress in unveiling the myth of rationality and decision-making since Simon (Simon, 1955; Simon $\&$ Holt, 1954) began this research program (see Cabantous \& Gond, 2011; Laroche, 1995; March, 2006). This study provides an exploratory model of how anger and fear can help or impede decision-making in the field. By seeking to get closer to the phenomenon of interest by observing leaders as they actively engage in actual decision-making and engaging participants in self-reflection, our model may more closely capture the reality of intuitive and rational decision-making than previous laboratory-based studies. This is especially appropriate in studying a phenomenon that resides outside the controlled confines of the laboratory in the real time, high stress, pressure cooker of actual groups and organizations.

\section{Appendix A. Glossary of key terms used in the film industry}

\section{A.1. Adjustment}

Adjusting an actor means to provide him or her with specific directions about how to change the way he or she is acting for the next take: tone of voice, facial expression, words, position, emotional expressiveness, etc.

\section{A.2. Assistant director (AD)}

The assistant director assists the director on a minute per minute basis. He or she relieves the director from all of the logistical aspects of the shoot, keeps things moving, brings actors on the set, stops traffic when the shoot is about to begin, asks set-designers and costume-designers to bring the props needed to the scene, etc. 


\section{A.3. Call-sheet}

A list of all the people who were present on set, their function and their contact.

\section{A.4. Director of photography (DP)}

The director of photography (DP) is in charge of the cinematography of the film, which includes lighting the set, and dynamically framing the shots. He or she manages the technical crew that operates the camera(s) and the lighting equipment. On the set, the DP makes decisions with the director about lighting, shots, angles, lenses, crane, etc.

\section{A.5. Film director}

The director of a film orchestrates the whole artistic part of the process of film-making. He or she translates the script on film, choosing locations, sets, angles of filming, lighting, special effects, editing, and directing actors' performances.

\section{A.6. Producer}

The producer of a film organizes the administrative aspects of the process of film-making - financing, marketing, distribution, legal issues, and planning of the production phase in conjunction with the director - and controls that the production stays on time and on budget.

\section{A.7. Production, pre-production, and post- production}

The artistic production of a film involves three phases. (1) In pre-production, the director and his or her key collaborators plan the shoot, selecting locations, casting and possibly rehearsing with actors, storyboarding the script, giving instructions for the building of sets and special effects devices, obtaining permits, and preparing the shooting program and the budget. (2) In the production phase, the film is actually shot on locations and sets with the whole film crew and cast. (3) In post-production, the film is edited, some special effects applied, the sound is retouched, and the music is added.

\section{A.8. Script supervisor}

Script supervisors are in charge of ensuring that continuity is preserved between scenes (e.g. that actors wear the same costumes or that props are in the same position).

\section{A.9. Shot-list}

The list of scenes to be shot, their order, the time they are expected to take to shoot, the crew and cast involved, and other information.

\section{References}

Adolphs, R., Tranel, D., \& Damasio, A. R. (2003). Dissociable neural systems for recognizing emotions. Brain and Cognition, 52(1), 61-69.
Agor, W. H. (1991). How intuition can be used to enhance creativity in organizations. Journal of Creative Behaviour, 25(1), 11-19.

Averill, J. R. (1982). Anger and aggression: An essay on emotion. New York: Springer-Verlag.

Bargh, J. A., \& Chartrand, T. (1999). The unbearable automaticity of being. American Psychologist, 54(7), 462-479.

Barsade, S. G., \& Gibson, D. E. (2007). Why does affect matter in organizations? Academy of Management Perspectives, 21(1), 36-59.

Bart, P., \& Guber, P. (2002). Shoot out: Surviving fame and (mis)fortune in Hollywood. New York: G.P. Putnam's Sons.

Bodenhausen, G. V., Sheppard, L. A., \& Kramer, G. P. (1994). Negative affect and social judgment: The differential impact of anger and sadness. European Jounal of Social Psychology, 24(1), 45-62.

Bolte, A., Goschke, T., \& Kuhl, J. (2003). Emotion and intuition: Effects of positive and negative mood on implicit judgments of semantic coherence. Psychological Sciences, 14(5), 416-421.

Brown, R., \& Kulik, J. (1977). Flashbulb memories. Cognition, 5(1), 73-99.

Burke, L., \& Miller, M. (1999). Taking the mystery out of intuitive decision making. Academy of Management Executive, 13(4), 91-99.

Cabantous, L., \& Gond, J.-P. (2011). Rational decision making as a performative practice: Explaining rationality's éternel retour. Organic Science, 22(3), 573-586.

Coget, J. F. (2009). Dialogical inquiry: An extension of Schein's clinical inquiry. Journal of Applied Behavioral Science, 45(1), 90-105.

Damasio, A. (1998). Descartes' error: Emotion, reason, and the human brain. New York: Bard/Avon Books.

Dane, E., \& Pratt, M. (2007). Exploring intuition and its role in managerial decision-making. Academy of Management Review, 32(1), 33-54.

Ekman, P. (1994). Strong evidence for universal in facial expressions: A reply to Russell's mistaken critique. Psychology Bulletin, 115(2), 268-287.

Elsbach, K., \& Barr, P. S. (1999). The effects of mood on individuals' use of structured decision protocols. Organic Science, 10(2), 181-198.

Epstein, S. (1998). Emotions and psychology from the perspective of cognitive-experiential self-theory. In W. Flack \& J. Laird (Eds.), Emotions in psychopathology: Theory and research. Affective Science (pp. 57-69). New York: Oxford University Press.

Ericsson, K. A., \& Charness, N. (1994). Expert performance. American Psychologist, 49(8), 725-747.

Estrada, C. A., Isen, A. M., \& Young, M. J. (1997). Positive affect facilitates integration of information and decreases anchoring in reasoning among physicians. Organic Behavior and Human Decision Processes, 72(1), 117-135.

Feldman, L. A. (1995). Variations in the circumplex structure of emotion. Personality and Social Psychology Bulletin, 21(8), 806-817.

Forgas, J. P. (1995). Mood and judgment: The affect infusion model (AIM). Psychology Bulletin, 117(1), 39-66.

Forgas, J. (1998). On being happy and mistaken: Mood effects on the fundamental attribution error. Journal of Personality and Social Psychology, 75(2), 318-331.

Frijda, N. H. (1986). The emotions. Cambridge: Cambridge University Press.

Geddes, D., \& Callister, R. R. (2007). Crossing the line: A dual threshold model of anger in organizations. Academy of Management Review, 32(3), 721-746.

Geertz, C. (1975). From the native's point of view. American Scientist, 63(1), 47-53.

George, J. M., \& Zhou, J. (2002). Understanding when bad moods foster creativity and good ones don't: The role of context and clarity of feelings. Journal of Applied Psychology, 87(4), 687-697. 
Giorgi, A. (1994). A phenomenological perspective on certain qualitative research methods. Journal of Phenomenological Psychology, 25(2), 190-220.

Giorgi, A., \& Giorgi, B. (2003). Phenomenology. In J. A. Smith (Ed.), Qualitative psychology: A practical guide to research methods (pp. 25-49). London: Sage.

Glaser, B., \& Strauss, A. (1967). The discovery of grounded theory. Chicago: Aldine.

Habermas, J. (1990). Moral consciousness and communicative action. Cambridge, MA: MIT Press.

Harper, P., Lima, C., \& Craufurd, D. (2000). Ten years of presymptomatic testing for Huntington's disease: The experience of the UK Huntington's disease prediction consortium. Journal of Medical Genetics, 37(10), 567-571.

Hensman, A., \& Sadler-Smith, E. (2011). Intuitive decision making in banking and finance. European Management Journal, 29(1), 51-66.

Hodgkinson, G., Langan-Fox, J., \& Sadler-Smith, E. (2008). Intuition: A fundamental bridging construct in the behavioural sciences. British Journal of Psychiatry, 99(1), 1-27.

Isen, A. M. (2000). Positive affect and decision making. In M. Lewis \& J. Haviland-Jones (Eds.), Handbook of emotions (pp. 417-435). New York: The Guilford Press.

Isen, A. M., Daubman, K. A., \& Nowicki, G. P. (1987). Positive affect facilitates creative problem solving. Journal of Personality and Social Psychology, 52(6), 1122-1131.

Isen, A. M., Johnson, M. M. S., Mertz, E., \& Robinson, G. (1985). The influence of positive affect on the unusualness of word associations. Journal of Personality and Social Psychology, 48(6), $1413-1426$.

Isen, A. M., \& Means, B. (1983). The influence of positive affect on decision-making strategy. Social Cognition, 2(1), 18-31.

Janis, I. L., \& Mann, L. (1977). Decision making: A psychological analysis of conflict, choice, and commitment. New York, USA: Free Press.

Jick, T. D. (1979). Mixing qualitative and quantitative methods: Triangulation in action. Administrative Science Quarterly, 24(4), 602-611.

Jordan, B., \& Henderson, A. (1995). Interaction analysis: Foundations and practice. Journal of Learning Sciences, 4(1), 39-103.

Kaempf, G., Klein, G., Thordsen, M., \& Wolf, S. (1996). Decision making in complex command-and-control environments. Human Factors, 38(2), 206-219.

Kahneman, D. (2003). A perspective on judgment and choice. Mapping bounded rationality. American Psychologist, 58(9), 697-720.

Kahneman, D., \& Klein, G. (2009). Conditions for intuitive expertise: A failure to disagree. American Psychologist, 64(6), 515-526.

Katkin, E. S., Wiens, S., \& Ohman, A. (2001). Nonconscious fear conditioning, visceral perception, and the development of gut feelings. Psychological Science, 12(5), 366-370.

Keltner, D., Ellsworth, P. C., \& Edwards, K. (1993). Beyond simple pessimism: Effects of sadness and anger on social judgment. Journal of Personality and Social Psychology, 64(5), 740-752.

Khatri, N., \& Ng, H. A. (2000). The role of intuition in strategic decision making. Human Relations, 53(1), 57-86.

Kihlstrom, J. F. (1987). The cognitive unconscious. Science, 237(4821), 1445-1452.

Kish-Gephart, J. J., Detert, J. R., Treviño, L. K., \& Edmondson, A. C. (2009). Silenced by fear: The nature, sources, and consequences of fear at work. Research in Organizational Behavior, 29, 163-193.

Klein, G. (1998). Sources of power: How people make decisions. Cambridge, MA: MIT Press.

Kohut, H. (1959). Introspection, empathy, and psychoanalysis: An examination of the relationship between mode of observation and theory. Journal of the American Psychoanalytic Association, 7, 459-483.

Laroche, H. (1995). From decision to action in organizations: Decision-making as a social representation. Organic Science, 6(1), 62-75.

Lazarus, R., \& Folkman, S. (1984). Stress, appraisal, and coping. New York: Springer.

LeDoux, J. E. (1996). The emotional brain: The mysterious underpinnings of emotional life. New York, NY: Simon \& Schuster.

Lerner, J. S., \& Keltner, D. (2000). Beyond valence: Toward a model of emotion-specific influences on judgment and choice. Cognition and Emotion, 14(4), 473-493.

Lerner, J. S., \& Keltner, D. (2001). Fear, anger, and risk. Journal of Personality and Social Psychology, 81(1), 146-159.

Lerner, J. S., \& Tiedens, L. Z. (2006). Portrait of the angry decision maker: How appraisal tendencies shape anger's influence on cognition. Journal of Behavioral Decision Making, 19(2), 115-137.

Lieberman, M. D. (2000). Intuition: A social cognitive neuroscience approach. Psychology Bulletin, 126(1), 109-137.

Lipshitz, R., Klein, G., Orasanu, J., \& Salas, E. (2001). Focus article: Taking stock of naturalistic decision making. Journal of Behavioral Decision Making, 14(5), 331-352.

Lipshitz, R., \& Shulimovitz, N. (2007). Intuition and emotion in bank loan officers' credit decisions. Journal of Cognitive Engineering and Decision Making, 1(2), 212-233.

Loewenstein, G. (1996). Out of control: Visceral Influences on Behavior. Organizational Behavior and Human Decision Processes, 65(3), 272-292.

Loewenstein, G., \& Lerner, J. S. (2003). The role of affect in decision making. In R. Davidson, K. Scherer, \& H. Goldsmith (Eds.), Handbook of affective science (pp. 619-642). New York: Oxford University Press.

Lubart, T., \& Getz, I. (1997). Emotion, metaphor, and the creative process. Creativity Research Journal, 10(4), 285-301.

Manicas, P. T., \& Secord, P. F. (1983). Implications for psychology of the new philosophy of science. American Psychologist, 38(4), 399-413.

March, J. G. (2006). Rationality, foolishness, and adaptive intelligence. Strategic Management Journal, 27(3), 201-214.

Miles, M. B., \& Huberman, M. A. (1994). Qualitative data analysis. Thousand Oaks, CA: Sage.

Pekrun, R., \& Friese, M. (1992). Emotions in work and achievement. International Review of Industrial and Organizational Psychology, 7, 153-200.

Rowe, J. O., Halling, S., Davies, E., Leifer, M., Powers, D., \& van Bronkhorst, J. (1989). The psychology of forgiving another: A dialogal research approach. In R. S. Valle \& S. Hailing (Eds.), Existential-phenomenological perspectives in psychology: Exploring the breadth of human experience (pp. 233-244). New York: Plenum Press.

Russell, J. A. (1999). Core affect, prototypical emotional episodes, and other things called emotion: Dissecting the elephant. Jorunal of Personality and Social Psychology, 76(5), 805-819.

Sadler-Smith, E. (2008). Inside intuition (New edition). London, UK: Routledge.

Sadler-Smith, E. (2010). The intuitive mind: Profiting from the power of your sixth sense. Chichester, UK: Wiley.

Sadler-Smith, E., \& Shefy, E. (2004). The intuitive executive: Understanding and applying 'gut feel' in decision-making. Academy of Management Executive, 18(4), 76-91.

Salas, E., Rosen, M. A., \& DiazGranados, D. (2010). Expertise-based intuition and decision making in organizations. Journal of Management, 36(4), 941-973.

Sandberg, J. (2005). How do we justify knowledge produced within interpretive approaches? Organic Research Methods, 8(1), 41-68. 
Sayegh, L., Anthony, W. P., \& Perrewé, P. (2004). Managerial decision-making under crisis: The role of emotion in an intuitive decision process. Human Resource Management Review, 14(2), 179-199.

Scherer, K. R. (1986). Vocal affect expression: A review and model for future research. Psychology Bulletin, 99(2), 143-165.

Simon, H. A. (1955). A behavioral model of rational choice. The Quarterly Journal of Economics, 69(1), 99-118.

Simon, H. A. (1968). Administrative behavior: A study of decisionmaking processes in administrative organization. New York: Macmillan.

Simon, H. A. (1987). Making management decisions: The role of intuition and emotion. Academy of Management Executive, 1(1), 57-64.

Simon, H. A., \& Holt, C. C. (1954). The control of inventories and production rates - A survey. Journal of the Operations Research Society of America, 2(3), 289-301.

Sinclair, M., \& Ashkanasy, N. M. (2005). Intuition: Myth or a decision-making tool. Management Learning, 36(3), 353-370.

Smith, S. (1998). The film 100: A ranking of the most influential people in the history of the movies. Los Angeles, CA: Citadel Press.

Smith, J. A., \& Osborn, M. (2003). Interpretative phenomenological analysis. In J. A. Smith (Ed.), Qualitative psychology: A practical guide to research methods (pp. 51-80). London: Sage.

Staw, B. M., \& Barsade, S. G. (1993). Affect and managerial performance: A test of the sadder-but-wiser vs. happier-andsmarter hypotheses. Administrative Science Quarterly, 38(2), 304-331.

Strijbos, J. W., Martens, R. L., Prins, F. J., \& Jochems, W. M. G. (2006). Content analysis: What are they talking about? Computers and Education, 46(1), 29-48.

Tiedens, L. Z., \& Linton, S. (2001). Judgment under emotional certainty and uncertainty: The effects of specific emotions on information processing. Journal of Personality and Social Psychology, 81(6), 973-988.

Von Neuman, J., \& Morgenstern, O. (1944). Theory of games and economic behavior. New York: Wiley.

Weick, K. E., Sutcliffe, K. M., \& Obstfeld, D. (2005). Organizing and the process of sensemaking. Organic Science, 16(4), 409-421.

Weiss, H. M., \& Cropanzano, R. (1996). Affective events theory: A theoretical discussion of the structure, causes and consequences of affective experiences at work. In B. M. Staw \& L. L. Cummings (Eds.), Research in Organizational Behavior (pp. 1-74). Greenwich, CT: JAI Press.

Woiceshyn, J. (2009). Lessons from "good minds"': How CEOs use intuition, analysis and guiding principles to make strategic decisions. Long Range Planning, 42(3), 298-319.

Zajonc, R. (1980). Feeling and Thinking. American Psychologist, 35(2), 151-175.

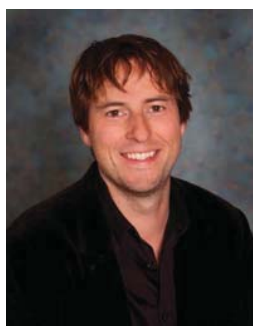

JEAN-FRANCCOIS COGET is an Associate Professor of Management at the Orfalea College of Business at CalPoly, San Luis Obispo, where he teaches Organizational Behavior and Training and Development, among other classes. He earned his Ph.D. in management from the Anderson School at UCLA, and was previously a faculty member at HEC Paris. His research interests include emotions, intuition, and charismatic leadership. His overarching professional goal is to create and disseminate actionable knowledge that can help managers-citizens to organize a productive, creative, ethical, and sustainable cooperation among people.

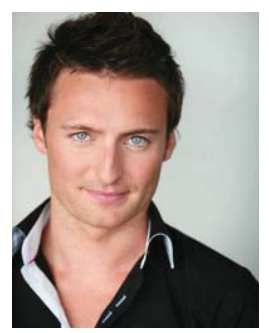

CHRIS is an Associate Professor of Organizational Behavior at EMLYON Business School. His research focuses on emotional intelligence and on the cathartic and catastrophic role of emotion in the intuitive decision making process.

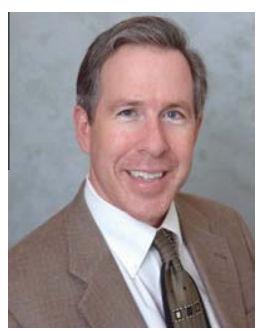

DON GIBSON is Professor of Management and Chair of the Management Department at the Charles F. Dolan School of Business, Fairfield University in Fairfield, Connecticut, where he teaches Management, Leadership, Human Resource Strategies, and Managing People for Competitive Advantage to undergraduate and graduate (MBA) students. He received his BS with honors from the University of California, Riverside, and an MA in Radio and Television from San Francisco State University. Don holds an MBA (1990) and Ph.D. (1995) from the University of California at Los Angeles. He was a faculty member for six years at Yale School of Management before joining the Dolan School of Business at Fairfield in 2001. Prior to his academic career, Don worked in international television and motion picture distribution for Lorimar Productions in Los Angeles. 